\title{
Health-related quality of life after tonsillotomy versus tonsillectomy in young adults: 6 years postsurgery follow-up
}

\author{
Sara Wireklint and Elisabeth Ericsson
}

\section{Linköping University Post Print}

N.B.: When citing this work, cite the original article.

The original publication is available at www.springerlink.com:

Sara Wireklint and Elisabeth Ericsson, Health-related quality of life after tonsillotomy versus tonsillectomy in young adults: 6 years postsurgery follow-up, 2012, European Archives of Oto-Rhino-Laryngology, (269), 8, 1951-1958.

http://dx.doi.org/10.1007/s00405-012-1990-y

Copyright: Springer Verlag (Germany) http://www.springerlink.com/?MUD=MP

Postprint available at: Linköping University Electronic Press http://urn.kb.se/resolve?urn=urn:nbn:se:liu:diva-79657 


\title{
Health-related Quality of Life after Tonsillotomy vs. Tonsillectomy
}

\author{
in Young Adults - 6 years Post-surgery follow-up
}

Sara Wireklint RN, $\mathrm{MscN}^{1,2}$, and' Elisabeth Ericsson CRNA, $\mathrm{PhD}^{1}$

${ }^{1}$ Divison of Nursing Science. Department of Medical and Health Sciences, Faculty of Health Sciences, Linköping University, Sweden. ${ }^{2}$ Emergency Clinic, Växjö Central Hospital, Växjö, Sweden

\section{Conflict of Interest: None}

Running title: Quality of Life after Tonsillotomy vs. Tonsillectomy

Corresponding author: Dr. Elisabeth Ericsson, Department of Medical and Health Sciences, Nursing Science Faculty of Health Sciences, Linköping University, SE-581 85 Linköping, Sweden; +46101037770 e-mail address elisabeth.ericsson@liu.se 


\begin{abstract}
Introduction: The indication for tonsil surgery is tonsillitis or obstructive symptoms due to tonsillar hypertrophy, associated with morbidity affecting health related quality of life (HRQL). Surgery performed is either tonsillectomy (TE) or partial intra capsular tonsillectomy/tonsillotomy (TT). TT is associated with fewer postoperative complications and rapid recovery, but with risk for regrowth of tonsillar tissue and return of sleep disordered breathing (SDB) or infections.
\end{abstract}

Aim: Investigate long-term effects of TT and TE in young adults relating to HRQL and well-being as consequence of obstructive symptoms or ENT-infections after six years vs. effect after one year.

Method: Young adults with symptoms of tonsillar hyperplasia were randomized to TE (44) or TT (32). Patients were assessed prior to surgery and one and six years postoperatively. Short Form 36 and the EuroQul Visual Analog Scale evaluated HRQL. Questionnaire was used to explore well-being, obstruction symptoms and infections. Patient BMI was calculated.

Results: Six years after surgery, 91\% of young adults (TE39/TT29) reported persisting benefits in well-being, reduced obstructive problems and fewer infections., Some patients in both groups reported slight increases in snoring compared to one year after surgery, but still less than before surgery. Obesity was more frequent among those snoring.

Conclusion: Both TT and TE in young adults yielded HRQL improvements and reduction in symptoms defining SDB persisting through six years post-surgery. Results indicate both surgical methods were equally effective. Findings favor choice of TT due to lesser postoperative morbidity.

KEYWORDS: Tonsillotomy, Tonsillectomy, Health Related Quality of Life, Sleep disorder, Tonsillar hypertrophy 


\section{Background}

Upper airway obstructive problems related to tonsillar hypertrophy are now the most common indication for tonsil surgery in children and youths as a result of improvements in the treatment for recurrent tonsillitis using antibiotics $^{1,2}$. If Tonsillotomy/Partial removal of the pharyngeal tonsils (TT) ${ }^{3}$ is performed, postoperative morbidity is decreased, reducing risk for readmission due to postoperative bleeding and hemorrhage ${ }^{4,5}$, dehydration or pain and shortening the time before return to work or school compared with total removal of the pharyngeal tonsils/tonsillectomy $(\mathrm{TE})^{1,3}$.The risk most frequently presumed from TT, is regrowth of tonsil tissue and thereby increased risk for Ear Nose and Throat (ENT)-infections or the return of obstructive problems ${ }^{1}$. In Sweden , approximately 12,500 undergo tonsil surgery per year of which about $50 \%$ are children less than 15 years-old, a considerable portion of the population ( 25\%) is between 16 and 25 years-old (National Tonsil Surgery Registry in Sweden) and seems to suffer more pain than younger patients ${ }^{3}$.

Sleep-disordered breathing (SDB) includes sleep problems such as obstructive sleep apnea (OSA), and upper airway resistance syndrome. SDB is a symptoms-complex; in youths and adults the symptoms range from snoring, cessation of breathing, dry mouth, morning headache, daytime sleepiness, and fatigue to daytime napping, mood changes and concentrations problems. Coexistence of obesity increases the morbidity of OSA ${ }^{6}$.

The cause-effect relationships between SDB, tonsillitis and illness as well as decreased Health Related Quality of Life (HRQL), have been largely overlooked and undertreated by health providers. Consensus is lacking on the definition of quality of life (QoL). A simple taxonomy divides Qol into global definitions and can be generalized to describe dimension of health, satisfaction, well-being or happiness. HRQL is the most commonly used definition refering only to the health of the patients ${ }^{7}$. The concept HRQL, originates from the World Health Organization's definition : "Health is a state of complete, physical, mental and social well-being and not merely the absence of disease or infirmity" ${ }^{\prime 2}$ The benefit of all tonsil surgery is improvement in HRQL with less infection, visits at the physician, and courses of antibiotics ${ }^{9,10}$. There are very few randomized studies with longterm follow-up of health and well-being after tonsil surgery. A previous study in children demonstrated substantial improvement in general HRQL and satisfaction in children after six months and after three years following tonsil surgery, but with no significant differences between $\mathrm{TT}$ and $\mathrm{TE}^{11}$. A study over a longer time period is needed to quantify the benefits of TE and TT in young adults. The aim of the present study is to investigate the long-term effects of tonsillotomy and tonsillectomy in young adults with regard to HRQL and well-being as a consequence of obstructive symptoms or ENT-infections after six years as compared with the effect after one year. 


\section{Method}

Permission to carry out the study was granted from the Regional Ethical Review Board in Linköping (Study code 03-449).

Young adults 16-25 years old with tonsillar hypertrophy and obstructive problems with or without recurrent infections on the waiting-list for tonsil surgery operated after randomization to either TE or TT. Exclusion criteria were patients who had been treated with antibiotics for throat infections during the last three months or had been treated for peritonsillitis ${ }^{3}$.

Seventy five patients (49 female and 26 males), were finally enrolled and operated in accordance with the randomization, $44 \mathrm{TE}$ and 32 TT. All but one of the patients had had episodes of sore throat preoperatively ${ }^{3}$. At the follow-up one year after surgery, 74 (43/TE and 31/TT) of the patients participated; one TE patient was excluded because of an incomplete questionnaire ${ }^{12}$.

In the present study, six years after the tonsil-surgery, all 75 young adults received a letter with information about the study together with the follow-up questionnaires. Two reminder letters were sent out after two and three weeks.

TT was performed with Ellman 4.0 MHz Surgitron Dual Radiowave Unit (Ellman International Oceanside NY) and TE was performed using cold knife and blunt dissection ${ }^{3}$.

After six years, assessments were performed in the same way as prior to and one year after surgery, i.e. with the Short form Health Survey (SF-36) ${ }^{13}$, Euroqul Visual Analogue Scale (EQ-VAS) ${ }^{14}$ and a questionnaire with questions about snoring, infection and health $(\mathrm{Qu})^{12}$. The $\mathrm{Qu}$ was augmented to include 19 questions on snoring and the potential risk factors associated with snoring ${ }^{15}$ and questions about weight and height.

$\underline{S F-36}$ is the HRQL instrument most frequently used today. It is a validated and generic life quality survey, which measures satisfactory health status as absence of limitations ${ }^{13}$. SF-36 generates information about eight specific dimensions: $P F$ (physical function), $R P$ (role limitation caused by physical problems), $B P$ (bodily pain), $G H$ (general health), VT (vitality), $S F$ (social function), $R E$ (role limitations caused by emotional problems), and $M H$ (mental health). The scores of all eight subscales are transformed to scale from 0 (worse score) to 100 (best score). These eight scores were also aggregated to two summary measures, the physical component summary score and the mental component summary score. 
Euroqul Visual Analogue Scale (EQ-VAS), is a self-rated health visual scale that is part of the EuroQol-5D ${ }^{14}$. EQ-VAS is presented as a thermometer with a scale from $0-100$, where 0 is the worst imaginable health status and 100 , the best possible. On this scale the patient marks their perceived health status on a particular day ${ }^{14}$.

$Q u$ is a questionnaire with semi-structured questions. The first part has been used in several follow-up tonsil studies to investigate general health, snoring and infections ${ }^{3,12}$. To further investigate the sleeping-problems related to snoring, the questionnaire has been augmented with questions from a sleep survey ${ }^{15}$. Included from this questionnaire were questions about sleep disturbances and associated day-time symptoms, somatic diseases, medication, height and weight, and questions about physical activity. All questions were assessed on a Likert scale.

Statistical analysis was performed using SPSS for Windows, Version 18. Descriptive data are expressed as number of cases and mean \pm standard deviation (SD). Parametric data were tested using Student's $t$ test (2-tailed) for normally distributed continuous variables.

Non-parametric analysis was used when the variables were at an ordinal level of measurement or if the data was not normally distributed (Kolmogorov-Smirnov test). Wilcoxon's signed rank test and Friedman-test were used to compare data over time on an individual level. The Mann-Whitney U-test was used to compare TT and TE. Correlation was calculated using Spearman rank correlation.

In all statistical analysis, $P$ values $<0.05$ were considered statistically significant.

Body mass index (BMI) was categorized into the following three groups in accordance with the WHO definitions: normal weight (BMI >18.5-24.9), pre-obese (BMI 25.0-29.9), and obese (BMI $\geq 30.0)^{16}$.

\section{Results}

The overall response rate at the six years follow-up was 91\% ( $\mathrm{N}=68), 39 \mathrm{TE}$ and $29 \mathrm{TT}$. Fifty-five percent required two mailings of the questionnaires before responding. In four cases (2TE/2TT), we were not able to find a mailing address; three of the four lived abroad. Four (3TE/1TT) were dropouts with no explanation.

The mean age of the study population was $25 \pm 3$ years; there were $23(34 \%)$ men and $45(66 \%)$ women $(\mathrm{p}<0.05)$. About $60 \%$ worked full time. The characteristics of the study population are presented in Table 1 . There were no age differences with respect to answers on the questionnaires (Qu, SF-36, EQ-5D VAS). 
Table 1. Characteristics of the study population six years after tonsils surgery

\begin{tabular}{|c|c|c|c|}
\hline Variables & $\begin{array}{c}\mathbf{T E} \\
\mathrm{n}=39\end{array}$ & $\begin{array}{c}\text { TT } \\
\mathrm{n}=29\end{array}$ & $\begin{array}{l}\text { Total } \\
\mathrm{n}=68\end{array}$ \\
\hline Age in years ${ }^{\text {a] }}$ & $25.6 \pm 3.2$ & $25.8 \pm 2.7$ & $25.7 \pm 3.0$ \\
\hline $\begin{array}{l}\text { Gender } \\
\text { ofemales } \\
\text { omales }\end{array}$ & $\begin{array}{c}30(77) \\
9(23)\end{array}$ & $\begin{array}{l}15(52) \\
14(48)\end{array}$ & $\begin{array}{l}45(66) \\
23(34)\end{array}$ \\
\hline $\begin{array}{l}\text { Occupation } \\
\text {-Work } \\
\text { oStudent } \\
\text { oUnemployed } \\
\text { o-Parental leave }\end{array}$ & $\begin{array}{c}21(54) \\
11(28) \\
3(8) \\
4(10)\end{array}$ & $\begin{array}{l}19(66) \\
6(21) \\
0(0) \\
4(14)\end{array}$ & $\begin{array}{l}40(58) \\
18(26) \\
3(4) \\
8(12)\end{array}$ \\
\hline $\begin{array}{l}\text { Snoring }{ }^{b]} \\
\text { } \text { Non Habitual snorers } \\
\text { } \text { Habitual }\end{array}$ & $\begin{array}{c}31(80) \\
8(20)\end{array}$ & $\begin{array}{c}25(86) \\
4(14)\end{array}$ & $\begin{array}{l}56(82) \\
12(18)\end{array}$ \\
\hline $\begin{array}{l}\text { Level of physical activity }{ }^{\text {b] }} \\
\text {-High } \\
\text { ॰Medium } \\
\text { ॰Medium low } \\
\text {-Low }\end{array}$ & $\begin{array}{l}4(10) \\
14(36) \\
15(39) \\
6(15)\end{array}$ & $\begin{array}{c}4(14) \\
5(17) \\
19(66) \\
1(3)\end{array}$ & $\begin{array}{c}8(12) \\
19(28) \\
34(50) \\
7(10)\end{array}$ \\
\hline $\begin{array}{l}B M I^{\text {a] }} \\
\text { ounder- and normal weight } \\
\text { op] } \\
\text { opre-obeses }{ }^{b]} \\
\text { obese }\end{array}$ & $\begin{array}{l}25.3 \pm 5.7 \\
25(64) \\
5(13) \\
9(23)\end{array}$ & $\begin{array}{c}25.7 \pm 4.6 \\
14(48) \\
11(38) \\
4(14)\end{array}$ & $\begin{array}{l}25.5 \pm 5.3 \\
39(57) \\
16(24) \\
13(19)\end{array}$ \\
\hline
\end{tabular}

${ }^{\mathrm{a}]}$ mean $\pm=\mathrm{SD}^{\mathrm{b}]}$ number (\%) TE=tonsillectomy TT=Tonsillotomy

Non-habitual snorers; score 1 through 3 (1=“never", 2 ="seldom", $3=$ ="sometimes") and habitual snorers; scores 4 and 5 (4="often", 5="very often").

Levels of physical activity; High = hard training, regular basis, several times a week Medium = daily life training, $3-4$ hours a week Medium low= e.g., biking to work, gardening Low = mostly sedentary activity

After their tonsil surgery, $75 \%$ reported no illnesses. $60 \%$ of the respondents reported no hospitalizations; the other $40 \%$ reported treatment for orthopedic, gynecologic, and for psychiatric problems.

BMI calculations showed that almost 50\% of the respondents were either pre-obese or obese in both groups.

Males had a higher average BMI than female patients $(\mathrm{p}<0.01)$, both preoperative and at time of follow-up. The mean weight gain and increase in BMI were significant between pre-surgery and six years post-surgery for both groups ( $\mathrm{p}<0.001$ ). Most of the respondents (60\%), 21/TE and 20/TT, reported a low level of physical activity; $12 \%$ were in hard training (Table I). The correlation between physical activity and BMI was $\mathrm{r}_{\mathrm{s}}=0.65(\mathrm{p}<0.001)$.

After six years, there was no significant difference between the TE and TT groups in frequency or loudness of snoring. No difference was found between the surgical groups on the other questions concerning sleep disorder, except that the TE-group scored higher on the topic, "tired during daytime" ( $<<0.05)$. Approximately $80 \%$ were non-habitual snorers in both groups (table 1). After six years, in both surgery groups the habitual snorers and occasional snorers were more frequently obese $(\mathrm{p}<0.01)$ and were less physically active compared with non- 
snorers $(\mathrm{p}<0.05)$. The female patients scored as more sleepy during the daytime $(\mathrm{p}<0.01)$ compared to the men regardless of surgery-group.

There were no significant differences between the groups with regard to ENT-infections. During the fifth year, eleven $(28 \%)$ patients received antibiotic treatment for infection in the ENT-area in the TE group vs. five (17\%) in the TT group as reported at the 6-year follow-up (table 2). More female patients than male patients had been treated for ENT-infections in proportion to their representation in the overall patient group $(\mathrm{p}<0.05)$. One TE who had one treatment period with antibiotics for sinusitis one year after surgery had the some problems with sinusitis after five years. The other patients which received antibiotic treatment for Upper Respiratory Infections (URI) during the fifth year following surgery had had no problems with URI at the one year follow-up (10TE/5TT).

Table 2. Upper Respiratory Infections treated with antibiotics during fifth year after tonsil-surgery

\begin{tabular}{|c|c|c|c|}
\hline & $\underset{(n=39)}{T E}$ & $\begin{array}{r}\text { TT } \\
(n= \\
29)\end{array}$ & $\begin{array}{l}\text { Tot } \\
\text { al } \\
(\mathrm{n}= \\
68)\end{array}$ \\
\hline & $\begin{array}{l}\text { Number } \\
(\%)\end{array}$ & & \\
\hline Sinusitis & $3(8)$ & & $3(4)$ \\
\hline Sore throat & $3(8)$ & 2(7) & $5(7)$ \\
\hline Pneumonia and sore throat & 1(3) & & $1(1)$ \\
\hline Otitis and sore throat & $2(5)$ & $2(7)$ & $4(6)$ \\
\hline Otitis & $2(5)$ & 1(3) & $3(4)$ \\
\hline Total numbers & $11(28)$ & $5(17$ & $16(2$ \\
\hline
\end{tabular}

TE=tonsillectomy TT=Tonsillotomy

The impact on HRQL in different surgical groups and the improvements after one and six years are presented in Table 3. Prior to surgery, both study groups reported a large negative impact on HRQL classified by SF-36 and EQ VAS. After one and six years, there were no differences between the groups except with regard to mental health $(\mathrm{p}<0.05)$. This could be explained by the fact that two patients reported depression $(1 \mathrm{TE} / 1 \mathrm{TT})$ and one TE Attention-Deficit/Hyperactivity Disorder (ADHD). After excluding these three patients (outliers) the difference between TT/TE was not significant.

Young adults showed significant improvements in all of the subscales of the physical dimensions. In the Physical Component Summary, the difference over time was large in both groups $(\mathrm{p}<0.001)$ when responses before surgery were compared one and six years after surgery. There were no differences between the scores after one year and after six years on any subscales (SF-36, EQ-VAS) between the TE and the TT-group. The 
Table 3. SF-36 Health Scale and EQ VAS: improvements one and six years after TE or TT compared to pre-surgery

\begin{tabular}{|c|c|c|c|c|c|c|c|c|c|c|c|c|c|}
\hline \multirow{2}{*}{ SF-36 Health Scales ${ }^{* *}$} & \multicolumn{3}{|c|}{$\begin{array}{l}\text { Before } \\
\text { surgery }\end{array}$} & \multicolumn{3}{|c|}{$\begin{array}{c}\text { One year } \\
\text { after surgery }\end{array}$} & \multicolumn{2}{|c|}{$\begin{array}{l}\text { Before/after } \\
\text { one yr. }\end{array}$} & \multicolumn{3}{|c|}{$\begin{array}{c}\text { Six years } \\
\text { after surgery }\end{array}$} & \multicolumn{2}{|c|}{$\begin{array}{l}\text { Before/after } \\
\text { six yrs. }\end{array}$} \\
\hline & $\underset{n=44}{T E}$ & $\underset{n=32}{T T}$ & TE/TT & $\begin{array}{c}\mathrm{TE} \\
\mathrm{n}=43\end{array}$ & $\underset{n=31}{T}$ & TE/TT & $\begin{array}{c}\text { TE } \\
(n=43)\end{array}$ & $\underset{(\mathbf{n}=31)}{\mathbf{T T}}$ & $\begin{array}{c}\mathrm{TE} \\
\mathrm{n}=39\end{array}$ & $\begin{array}{c}\text { TT } \\
n=29\end{array}$ & TE/TT & $\underset{(n=39)}{\mathbf{T E}}$ & $\underset{(n=29)}{\text { TT }}$ \\
\hline Physical dimension & & & $p$-value ${ }^{\text {a) }}$ & & & $p$-value ${ }^{\text {a) }}$ & $p$-value & $p$-value $\mathrm{e}^{\mathrm{b})}$ & & & $p$-value ${ }^{\text {a) }}$ & $p$-value ${ }^{\text {b) }}$ & $p$-value ${ }^{\text {b) }}$ \\
\hline $\begin{array}{l}\text { Physical Functioning } \\
{[\mathrm{PF}]}\end{array}$ & $88.1 \pm 13.7$ & $92.0 \pm 9.5$ & NS & $97.2 \pm 5.6$ & $97.6 \pm 6.1$ & NS & $<.001$ & $<.001$ & $96.6 \pm 7.4$ & $97,4 \pm 4.1$ & NS & $<.001$ & $<.01$ \\
\hline $\begin{array}{l}\text { Role Functioning- } \\
\text { Physical [RP] }\end{array}$ & $62.5 \pm 37.2$ & $64.1 \pm 40.1$ & NS & $91.9 \pm 22.9$ & $93.6 \pm 19.3$ & NS & $<.001$ & $<.01$ & $90.4 \pm 21.9$ & $93.1 \pm 17.5$ & NS & $<.001$ & $<.01$ \\
\hline Bodily Pain [BP] & $59.9 \pm 27.0$ & $67.9 \pm 22.9$ & NS & $85.8 \pm 19.1$ & $88.1 \pm 19.7$ & NS & $<.001$ & $<.01$ & $76.8 \pm 26.7$ & $88.6 \pm 20.3$ & NS & $<.01$ & $<.01$ \\
\hline General Health [GH] & $41.4 \pm 21.1$ & $56.8 \pm 27.1$ & $<.05$ & $67.7 \pm 22.4$ & $71.3 \pm 19.8$ & NS & $<.001$ & $<.001$ & $66.2 \pm 23.9$ & $79.4 \pm 17.2$ & NS & $<.001$ & $<.001$ \\
\hline $\begin{array}{l}\text { Mental dimension } \\
\text { Vitality [VT] }\end{array}$ & $42.9 \pm 23.8$ & $46.3 \pm 19.0$ & NS & $60.5 \pm 24.6$ & $69.4 \pm 18.7$ & NS & $<.001$ & $<.001$ & $54.2 \pm 25.9$ & $66.9 \pm 16.4$ & NS & $<.05$ & $<.001$ \\
\hline Social functioning $[\mathrm{SF}]$ & $74.4 \pm 25.7$ & $82.8 \pm 21.3$ & NS & $87.2 \pm 20.7$ & $91.1 \pm 15.5$ & NS & $<.001$ & NS & $78.8 \pm 26.8$ & $90.9 \pm 15.6$ & NS & NS & NS \\
\hline $\begin{array}{l}\text { Role functioning- } \\
\text { emotional [RE] }\end{array}$ & $68.9 \pm 42.8$ & $82.3 \pm 29.3$ & NS & $79.8 \pm 34.9$ & $90.3 \pm 24.6$ & NS & NS & NS & $75.2 \pm 38.0$ & $90.8 \pm 21.6$ & NS & NS & NS \\
\hline Mental Health [MH] & $68.9 \pm 23.7$ & $75.0 \pm 13.0$ & NS & $73.3 \pm 22.3$ & $84.7 \pm 13.7$ & $<.05$ & NS & $<.01$ & $68.7 \pm 23.7$ & $80.7 \pm 17.9$ & $<.05$ & NS & $<.05$ \\
\hline PCS & $43.9 \pm 8.4$ & $46.1 \pm 9.0$ & NS & $54.4 \pm 5.5$ & $53.4 \pm 5.9$ & NS & $<.001$ & $<.001$ & $54.1 \pm 5.0$ & $53.8 \pm 5.0$ & NS & $<.001$ & $<.001$ \\
\hline MCS & $41.2 \pm 13.9$ & $45.3 \pm 8.5$ & NS & $44.1 \pm 13.3$ & $49.9 \pm 9.2$ & NS & NS & $<.05$ & $43.2 \pm 12.8$ & $44.4 \pm 15.2$ & NS & NS & NS \\
\hline EQ VAS ${ }^{*}$ & $67.6 \pm 18.9$ & $73.5 \pm 19.6$ & NS & $78.7 \pm 17.6$ & $84.5 \pm 14.5$ & NS & $<.001$ & $<.001$ & $72.7 \pm 21.2$ & $81.7 \pm 16$ & NS & $<.05$ & $<.01$ \\
\hline
\end{tabular}

health scales. Physical dimension: $\mathrm{PF}=$ Ability to perform daily physical activities, e.g., walking, running, lifting and other moderate physical efforts, $\mathrm{RP}=$ Extent to which physical health limits work/daily activities; $\mathrm{BP}=$ Intensity of pain and its interference with normal activities; $\mathrm{GH}=$ Personal evaluation of general health status, presently and in the future. Mental dimension: $\mathrm{VT}=$ Personal evaluation of energy, tiredness. etc.; $\mathrm{SF}=$ Extent to which physical health or emotional problems interfere with normal social activities; $\mathrm{RE}=$ Extent to which emotional problems limit work/daily activities; $\mathrm{MH}=$ Personal evaluation of mental health, including anxiety, depression and general positive and negative affects ${ }^{10,11}$. Two summary scores: PCS = Physical Component Summary and MCS $=$ Mental Component Summary (MCS)."EQ VAS= EuroQul Visual Analogue Scale, self-rated health visual scale

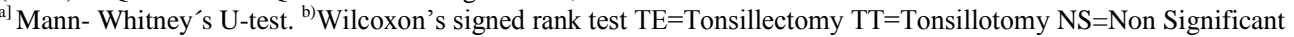


self-reported overall health as measured on the EQ VAS was improved in both groups after one year $(\mathrm{p}<0.001)$; this improvement remained after six years in TT $(\mathrm{p}<0.01)$ and TE $(<0.05)$.

For the question asking if the patient was satisfied with the results of the tonsil-operation compared to the situation before surgery, both groups were satisfied (96\% TE and 90\% TT) with no significant difference. The persons who were habitual snorers after six years were less satisfied with the surgery $(\mathrm{p}<0.001)$ compared to non-snorers. Two patients scored "less satisfied" due to URI after surgery (1TE/1TT). Both had also been treated with antibiotics for sore throat during the last 12 months. One TT scored "not at all satisfied" because they experienced substantially increased snoring post-surgery. One TE scored "somewhat worse" due to feeling more tired during the day and having gained weight (habitual snorer). One TT scored "somewhat worse" due to illness in MbCrohn and one TT due to weight gain (no habitual snoring).

\section{Discussion}

The main finding in the present study is that traditional TE and TT both yield equally good long term results on HRQL after tonsil surgery in young adults with obstructive symptoms due to tonsillar hypertrophy. After six years, most of the respondents in both surgery groups still reported improved self-rated health and HRQL compared to before surgery; no difference was found between the two interventions. There was an increase in snoring after 6 years, but there was no difference between TT and TE regarding either snoring or sleep pattern.

BMI was calculated and the patients estimated their physical activity. Average BMI was high and there was a predominance of low physical activity that could have caused resumption of snoring. The majority of the patients from both groups had stayed healthy after their tonsil surgery. Only a few patients (2TE/2TT) were unsatisfied with the tonsil surgery; these were among those with high BMI and low physical activity.

In this study, patients had surgery primarily due to obstructive symptoms and to some extent due to recurrent tonsillitis. The results show a continued high proportion of non-habitual snorers. Despite the fact that the number of habitual snorers had increased since the one year follow-up, it is still a clear improvement compared to before the tonsil-surgery. No difference between TT and TE was found, which is consistent with Hultcrantz et al.(2005) ${ }^{17}$. In their ten year follow-up of OSA patients treated either with TT or TE, another research group found no difference between the groups, suggesting that since there were no differences in amount of snoring, TT can be used as treatment for $\mathrm{SDB}^{18}$. 
Since overweight and obesity interact and affect SDB in both adults and children, it is also a factor that must be considered. It is sometimes difficult to determine whether obesity causes OSA, or if OSA causes obesity ${ }^{19}$. Some authors even purpose a need for classification to enable better treatment, declaring that there are two types; "type I OSA" is applied when there is hypertrophic lymphoid tissue and absence of obesity and "type II OSA" is applied when patients present with obesity, but only slight hypertrophy ${ }^{20}$.

For the reasons given above, BMI was calculated for the patients in the present investigation to give a broader picture of the basis of their snoring. When considered in relation to the patients' self-estimated physical activity, a pattern was discernible; there is an inverse correlation between physical activity and BMI. There is also a correlation between physical activities and OSA in that it has been found that even a small amount of physical activity improves HRQL for patients with moderate $\mathrm{OSA}^{21}$. In a study of lifestyle interventions to treat mild OSA, the authors concluded that for this category of patients, weight loss should be considered as a golden standard since it yields clear positive effects on morbidity and is an easy way to approach the phenomenon. Their argument is strengthened by findings that in this patient group there is poor adherence to today's first choice of treatment, $\mathrm{CPAP}^{22}$. Both obesity and asthma are considered risk factors for snoring ${ }^{19}$. In present study, The diagnosis asthma was frequent among the patients who were habitual snorers, which can be one explanation for the increased severity in snoring among these patients.

It is difficult to determine severity of SDB in the patients before surgery and at follow-ups, since no sleep recordings of the patients were done in the present study. (Sleep recordings are not considered necessary for this type of patients in Sweden.)

No difference was found in rates of infections between groups. Both intervention groups had a slight increase in ENT infections compared to the one year follow-up, but the difference was not significance. Though not significant, only patients from the TE group reported that they have many more ENT infections six years after operation. Even though no difference was found in the frequency of URI infections between TT/TE patients, only one of the patients (TE), treated for URI at the one year follow-up, still had the same problem (TE); all the others reporting URI at six years had scored "none" five years earlier. Most patients in the present study had obstructive problems as the main indication for surgery, which perhaps influenced this result. 
In contrast with studies claiming that patients who undergo TT are at increased risk for recurrent infections ${ }^{1}$, the present study supports the results in Reichel et al. $(2007)^{5}$ not showing any such increased risk after TT as compared to TE.

The possibility of immunological problems that can occur after tonsil-surgery must be carefully considered, since the function of tonsils in the immunological system not is entirely clear ${ }^{23}$. One study found no difference in the levels of immunological parameters 54 months after surgery ${ }^{24}$. In contrast, another investigation showed increased risk for developing chronic diseases such as asthma, ulcerative colitis, goiter and arterial hypertension in a twenty-year follow-up study ${ }^{25}$.

Due to their problems with snoring and infections, patients in the current study scored significantly lower on HRQL preoperatively as compared with a Swedish normal population. Large improvements in average scores were seen in both surgical groups after one year with transition toward normal values ${ }^{12}$ and remaining after six years. Three patients scored somewhat worse at six-years than preoperatively. Two of them (1TT/1TE) scored worse due to weight gain, but only one of them was also considered a habitual snorer (TE). The third (TT) patient scored worse related to an Mb Crohn condition.

HRQL includes subjective feelings of functional status, general health, well-being and appreciation of life. One year after tonsil surgery, all patients were significantly improved in their HRQL ${ }^{12}$. This study demonstrates that after six years, patients still retain this improvement except with respect to one item, mental health. However, if one removes the three patients (2TE/1TT) with diagnosed mental disorders from the analysis, there are no differences between results at one-year and in the current study. Hence, it can be noted that even those patients with chronic illnesses rated their mental health higher in the present study than before the surgery. There was no difference between TT and TE in the degree of improvement in HRQL at the one-year and six-year follow-ups.

It is difficult to define HRQL; it is therefore of great importance to use the best available instrument. If the patient is the respondent, it is important to be confident that that they are the best source in the matter ${ }^{26}$. SF 36 is a self-assessment instrument giving a rough picture of how the individuals perceive their health. Combined with a specific instrument, here the $\mathrm{Qu}$, a good assessment can be obtained. The Tonsil and Adenoid Health Status Instrument (TASHI) is a disease-specific questionnaire for tonsil and adenoid problems ${ }^{10}$. However, the patient group in the current study was approached before 2008 and the TASHI was not then available in Sweden. Since the Qu already had been used by these patients, it was a well-known instrument for them. Using SF-36 and EQ 
VAS, the present study shows that the beneficial impact on HRQL persisted in the long-term. The Qu adds as a complement, the details such as snoring, sleep and infection.

Several previous studies have demonstrated improved HRQL after tonsillectomy supposedly due to reduced morbidity from SDB and infections ${ }^{10,27}$. There are also several studies discussing the long-term effect on HRQL after tonsillectomy, both in adults and in children. Although these authors do not measure the effects over the same amount of time and use different HRQL instruments, they all demonstrate the same lasting effects ${ }^{28,29}$.

Interestingly, this study showed a rather high BMI for the patients. Almost $50 \%$ of the patients were pre-obese or obese. One study followed a large number of persons for two decades, concluding that those who were obese in young adult-hood had a higher risk of deteriorated physical HRQL as adults ${ }^{30}$. It has also been demonstrated that factors directly causing a change in either BMI or SDB are always associated with changes in the other. SDB results in day-tiredness and that no energy is left to be physically active. This can lead to weight gain and thereby more tiredness such that it becomes a vicious circle ${ }^{19}$. The greater the severity of SDB, the larger the impact on $\mathrm{HRQL}^{21}$. This is consistent with results for patients in the present study since they report that their snoring is not as severe as it was before surgery.

It is interesting to note the tiredness/fatigue reported by a few patients. This can be considered in relation to a study of males and females with untreated $\mathrm{OSA}^{31}$, where the authors suggested a relationship between OSA fatigue, depressed mood, increased BMI and a sleep-related component of inflammation.

Finally one should bear in mind that HRQL is affected by many things at the same time, for example unemployment, family situation and self-esteem ${ }^{32}$. Even physical activity can have an influence on perceived HRQL; thus the amount of patients' physical activity could influence the results in present study.

The present study is one of very few randomized studies that compare HRQL between TE and TT in young adults for such a long period. The high response rate after six years strengthens the results for this study.

On the other hand, it is a limitation that there was no direct contact with the patients; contact was only by mail. There was also no assessment of physical activity preoperatively and at the one year follow-up. Therefore, it is difficult to draw conclusions about how physical activity can have affected HRQL. An additional weakness is that no sleep studies were done to demonstrate objective outcomes. The large number of females among the respondents is consistent with Stalfors et al. [2012], who found that females in the age group 12 to approximately 21 years are more likely to have tonsil surgery. 


\section{Quality of Life after Tonsillotomy vs. Tonsillectomy}

\section{Conclusion}

It appears that TT yields equally good long term effects as TE regarding HRQL, snoring and ENT-infections in young adults with tonsil hypertrophy. Benefits of the TT procedure compared to TE including less pain, fewer postoperative complications and rapid recovery should be taken in account when the decision is made that a patient needs tonsil surgery.

Further investigation with a qualitative design could give a deeper understanding of HRQL for these patients' preoperatively and at follow-ups.

Acknowledgement

The author wants to thank all those who willingly participated in this study.

\section{Conflict of Interest: None}




\section{References}

1. Koempel JA, Solares CA, Koltai PJ. The evolution of tonsil surgery and rethinking the surgical approach to obstructive sleep-disordered breathing in children. J Laryngol Otol. Dec 2006;120(12):993-1000.

2. Stalfors J, Ericsson $\mathrm{E}$, Hemlin $\mathrm{C}$, et al. Tonsil surgery efficiently relieves symptoms: analysis of 54696 patients in the National Tonsil Surgery Register in Sweden. Acta oto-laryngologica. Jan 112012.

3. Ericsson E, Hultcrantz E. Tonsil surgery in youths: good results with a less invasive method. Laryngoscope. Apr 2007;117(4):654-661.

4. Hessen Soderman AC, Ericsson E, Hemlin C, et al. Reduced risk of primary postoperative hemorrhage after tonsil surgery in Sweden: results from the National Tonsil Surgery Register in Sweden covering more than 10 years and 54,696 operations. The Laryngoscope. Nov 2011;121(11):2322-2326.

5. Reichel O, Mayr D, Winterhoff J, de la Chaux R, Hagedorn H, Berghaus A. Tonsillotomy or tonsillectomy?--a prospective study comparing histological and immunological findings in recurrent tonsillitis and tonsillar hyperplasia. Eur Arch Otorhinolaryngol. Mar 2007;264(3):277-284.

6. Baldwin CM, Quan SF. Sleep disordered breathing. Nurs Clin North Am. Dec 2002;37(4):633-654, vi.

7. Farquhar M. Definitions of quality of life: a taxonomy. J Adv Nurs. Sep 1995;22(3):502-508.

8. WHO. Constitution of the World Health Organization, Geneva. 1946. Accessed September 2011.

9. Bhattacharyya N, Kepnes LJ, Shapiro J. Efficacy and quality-of-life impact of adult tonsillectomy. Arch Otolaryngol Head Neck Surg. Nov 2001;127(11):1347-1350.

10. Witsell DL, Orvidas LJ, Stewart MG, et al. Quality of life after tonsillectomy in adults with recurrent or chronic tonsillitis. Otolaryngol Head Neck Surg. Jan 2008;138(1 Suppl):S1-8.

11. Ericsson E, Graf J, Hultcrantz E. Pediatric tonsillotomy with radiofrequency technique: long-term follow-up. Laryngoscope. Oct 2006;116(10):1851-1857.

12. Ericsson $\mathrm{E}$, Ledin $\mathrm{T}$, Hultcrantz E. Long-term improvement of quality of life as a result of tonsillotomy (with radiofrequency technique) and tonsillectomy in youths. Laryngoscope. Jul 2007;117(7):1272-1279.

13. Sullivan M, Karlsson J, Ware JE, Jr. The Swedish SF-36 Health Survey; Evaluation of data quality, scaling assumptions, reliability and construct validity across general populations in Sweden. Soc Sci Med. Nov 1995;41(10):1349-1358.

14. Brooks R. EuroQol: the current state of play. Health Policy. Jul 1996;37(1):53-72.

15. Svensson M, Franklin KA, Theorell-Haglow J, Lindberg E. Daytime sleepiness relates to snoring independent of the apnea-hypopnea index in women from the general population. Chest. Nov 2008;134(5):919-924.

16. WHO. Obesity and overweight. Accessed 2011september http://www.who.int/mediacentre/factsheets/fs311/en/.

17. Hultcrantz $E$, Linder A, Markstrom A. Long-term effects of intracapsular partial tonsillectomy (tonsillotomy) compared with full tonsillectomy. Int J Pediatr Otorhinolaryngol. Apr 2005;69(4):463-469. 
18. Eviatar E, Kessler A, Shlamkovitch N, Vaiman M, Zilber D, Gavriel H. Tonsillectomy vs. partial tonsillectomy for OSAS in children-10 years post-surgery follow-up. Int J Pediatr Otorhinolaryngol. Jan 212009.

19. Carter R, 3rd, Watenpaugh DE. Obesity and obstructive sleep apnea: Or is it OSA and obesity? Pathophysiology. Aug 2008;15(2):71-77.

20. Dayyat E, Kheirandish-Gozal L, Gozal D. Childhood Obstructive Sleep Apnea: One or Two Distinct Disease Entities? Sleep Med Clin. Sep 2007;2(3):433-444.

21. Lopes C, Esteves AM, Bittencourt LR, Tufik S, Mello MT. Relationship between the quality of life and the severity of obstructive sleep apnea syndrome. Braz J Med Biol Res. Oct 2008;41(10):908-913.

22. Tuomilehto HP, Seppa JM, Partinen MM, et al. Lifestyle intervention with weight reduction: first-line treatment in mild obstructive sleep apnea. Am J Respir Crit Care Med. Feb 15 2009;179(4):320-327.

23. Brandtzaeg P. Immunology of tonsils and adenoids: everything the ENT surgeon needs to know. Int J Pediatr Otorhinolaryngol. Dec 2003;67 Suppl 1:S69-76.

24. Kaygusuz I, Alpay HC, Godekmerdan A, et al. Evaluation of long-term impacts of tonsillectomy on immune functions of children: a follow-up study. Int J Pediatr Otorhinolaryngol. Mar 2009;73(3):445-449.

25. Johansson E, Hultcrantz E. Tonsillectomy--clinical consequences twenty years after surgery? Int J Pediatr Otorhinolaryngol. Sep 2003;67(9):981-988.

26. Moyer CA, Sonnad SS, Garetz SL, Helman JI, Chervin RD. Quality of life in obstructive sleep apnea: a systematic review of the literature. Sleep Med. Nov 2001;2(6):477491.

27. Koskenkorva $T$, Koivunen $\mathrm{P}$, Penna $\mathrm{T}$, Teppo $\mathrm{H}$, Alho OP. Factors affecting quality-oflife impact of adult tonsillectomy. J Laryngol Otol. Sep 2009;123(9):1010-1014.

28. Akgun D, Seymour FK, Qayyum A, Crystal R, Frosh A. Assessment of clinical improvement and quality of life before and after tonsillectomy. J Laryngol Otol. Feb 2009;123(2):199-202.

29. Baldassari CM, Mitchell RB, Schubert C, Rudnick EF. Pediatric obstructive sleep apnea and quality of life: a meta-analysis. Otolaryngol Head Neck Surg. Mar 2008;138(3):265-273.

30. Kozak AT, Daviglus ML, Chan C, Kiefe Cl, Jacobs DR, Jr., Liu K. Relationship of body mass index in young adulthood and health-related quality of life two decades later: the Coronary Artery Risk Development in Young Adults study. Int J Obes (Lond). Jun 152010.

31. Mills PJ, Kim JH, Bardwell W, Hong S, Dimsdale JE. Predictors of fatigue in obstructive sleep apnea. Sleep Breath. Nov 2008;12(4):397-399.

32. Axelsson L, Andersson IH, Eden L, Ejlertsson G. Inequalities of quality of life in unemployed young adults: a population-based questionnaire study. Int J Equity Health. 2007;6:1. 